\title{
Effects of Processing Conditions and Plasticizing-Reinforcing Modification on the Crystallization and Physical Properties of PLA Films
}

\author{
Shuo Wang, Baodong Liu, Yingying Qin and Hongge Guo * \\ School of Light Industry Science and Engineering, Qilu University of Technology, Jinan 250353, China; \\ 10431200886@stu.qlu.edu.cn (S.W.); lbd980918@163.com (B.L.); 17862977017@139.com (Y.Q.) \\ * Correspondence: ghg@qlu.edu.cn
}

check for updates

Citation: Wang, S.; Liu, B.; Qin, Y.; Guo, H. Effects of Processing Conditions and Plasticizing-Reinforcing Modification on the Crystallization and Physical Properties of PLA Films. Membranes 2021, 11, 640. https:// doi.org/10.3390/membranes11080640

Academic Editor: Alexander Toikka

Received: 27 July 2021

Accepted: 17 August 2021

Published: 20 August 2021

Publisher's Note: MDPI stays neutral with regard to jurisdictional claims in published maps and institutional affiliations.

Copyright: (C) 2021 by the authors. Licensee MDPI, Basel, Switzerland. This article is an open access article distributed under the terms and conditions of the Creative Commons Attribution (CC BY) license (https:// creativecommons.org/licenses/by/ $4.0 /)$.

\begin{abstract}
The polylactic acid (PLA) resin Ingeo 4032D was selected as the research object. Epoxy soybean oil (ESO) and zeolite (3A molecular sieve) were used as plasticizer and reinforcing filler, respectively, for PLA blend modification. The mixture was granulated in an extruder and then blown to obtain films under different conditions to determine the optimum processing temperatures and screw rotation. Then, the thermal behaviour, crystallinity, optical transparency, micro phase structure and physical properties of the film were investigated. The results showed that with increasing zeolite content, the crystallization behaviour of PLA changed, and the haze of the film increased from $5 \%$ to $40 \%$ compared to the pure PLA film. Zeolite and ESO dispersed in the PLA matrix played a role in toughening and strengthening. The PLA/ $8 \mathrm{wt} \%$ zeolite $/ 3 \mathrm{wt} \%$ ESO film had the highest longitudinal tensile strength at $77 \mathrm{MPa}$. The PLA/2 wt\% zeolite/3 wt $\%$ ESO film had the highest longitudinal elongation at $13 \%$. The physical properties depended heavily on the dispersion of zeolite and ESO in the matrix.
\end{abstract}

Keywords: polylactic acid blown film; processing conditions; crystallization; physical properties; DSC analysis

\section{Introduction}

The global annual consumption of plastics reached 500 million tons in 2019; the huge amount of discarded plastic caused severe and irreversible environmental pollution. The development of biodegradable plastics can fundamentally solve the problem, and has therefore become one of the most important research topics [1].

Polylactic acid (PLA) is a new biobased and renewable biodegradable material. It is made of materials containing starch from renewable plants (such as corn, wheat, and cassava) [2-4]. Glucose is obtained from starch raw material through saccharification, and then high-purity lactic acid is produced by fermentation of glucose and certain bacteria. Then, PLA with a certain molecular weight is synthesized by chemical synthesis. It can be completely degraded by microorganisms in nature under specific conditions, resulting in carbon dioxide and water, and is recognized as an environmentally-friendly material [5-8]. Some brands of PLA resin with a strength up to $54.69 \mathrm{MPa}$ are accepted as representatives to replace petroleum-based plastics, such as PE and PP. However, the inherent high brittleness and low toughness of PLA (e.g., elongation at a break of 7.69\%, notched impact strength of $2.33 \mathrm{~kJ} / \mathrm{m}^{2}$ ) and its high cost severely restrict its wide application [1]. Used as packaging film, PLA resin has high crystal transparency, good solvent resistance (insoluble in alcohols, fats, hydrocarbons, edible oils, and mechanical oils), lower temperature heat sealing ability, better printability than polyolefins, and good ink retention, which can retain the flavour and package aesthetics of foods to a greater extent [9]. However, it still has low flexibility, slow crystallization rate, low crystallinity and weak barrier properties [10].

Recently, many experts have paid attention to the modification of PLA by physical and chemical methods to overcome its inherent shortcomings [11-19]. PLA resin blended with 
cellulose [20], cellulose fiber [21,22] and poly (butylene adipate-coterephthalate) (PBAT) will also improve the packaging properties of PLA film [23]. Fillers, such as montmorillonite (MMT), are natural clays with a high specific surface area that can potentially produce "nano barrier walls" within the nanocomposites. Organically modified montmorillonite (OMMT) is used to achieve an improved dispersion effect within the PLA matrix [24]. Jong et al. [25] fabricated PLA-based composite films with different types of nanoclays by solvent casting. They found that the water resistance of PLA films improved to different degrees.

A biodegradable citrate ester plasticizer and vegetable oil-based epoxidized soybean oil (ESO) plasticizer toughened PLA in nearly ten years. The mechanical properties, thermal resistance, crystalline behaviors and processing performance changed $[1,26]$. Copolymerization with other monomers is another approach that has been used to improve the properties such as stiffness, permeability, crystallinity, and thermal stability [8,27-29]. Covalent immobilization of polypeptides on PLA films can make it an active packaging [30]. Adding filler and plasticization was explored as an economically viable way to modify the properties of PLA resin. Ingeo Series (Nature work company, Blair, NE, USA) is a high heat-resistant brand in PLA resin and can be used as a basic resin to further optimize the comprehensive properties of modified materials.

Zeolites are hydrous aluminosilicate minerals with network structures. 3A molecular sieve zeolites are layered inorganic nanomaterials that can be used as fillers, nucleating agents and ethanol and water separation in polymers. Zeolites can improve the mechanical properties, increase crystallinity and transfer water vapor and breathing gas as an active packaging bag.

Epoxidized soybean oil (ESO) is recognized as a potential reactive plasticizer with the advantages of low cost, biodegradability, renewability, and availability. ESO is a foodgrade additive synthesized from soybean oil through the epoxidation of $\mathrm{C}=\mathrm{C}$ bonds in the fatty acid chains. ESO is composed of three long and flexible aliphatic chains, and its epoxy functional groups on the chains can react with the $-\mathrm{OH}$ and $-\mathrm{COOH}$ groups on other polymers. When the long flexible aliphatic chains of ESO were added to polymers, the copolymer resin formed between ESO and polymers had a lower cross-link density, increasing the flexibility of the polymers and significantly reducing the brittleness [31].

Therefore, ESO was used as a plasticizer and zeolite was used as reinforcing fillers, and the PLA blend was mixed by melting extrusion, cooled with water and granulated. Then, the film was blow-moulded to fit a specific blow-up and draw ratio. The studies were focused on different ratios of zeolite and ESO and their interactions with the crystallization and physical properties of PLA films.

\section{Experimental}

\subsection{Materials}

PLA (Ingeo 4032D) was purchased from Nature Works Company (Blair, NE, USA). At a temperature of $190^{\circ} \mathrm{C}$, loading pressure of $2.16 \mathrm{~kg}$ and cutting time interval of $30 \mathrm{~s}$, the MFR of Ingeo 4032D PLA was $5.872 \mathrm{~g} / 10 \mathrm{~min}$.

Epoxidized soybean oil (ESO) was purchased from Xinjinlong Plastic Additives Co., Ltd. (Guangzhou, China).

Zeolite (3A molecular sieve, with an average particle size of 2-5 $\mu \mathrm{m}$ ) was purchased from Yuanli Chemical Co., Ltd. (Tianjin, China).

\subsection{Manufacturing Methods}

Pretreatment: PLA and zeolite were dried separately in a vacuum drying oven at $80^{\circ} \mathrm{C}$ and $105^{\circ} \mathrm{C}$ for $4 \mathrm{~h}$.

Mixed granulation: Zeolite was soaked in ESO and stirred with PLA particles in a mixer in different proportions and left in the sealed mixer for $24 \mathrm{~h}$ (recipe as per Table 1), and the granular resin for the blowing film was produced by the single screw extruder. 
Table 1. Experiment recipe.

\begin{tabular}{cccc}
\hline Samples & $\begin{array}{c}\text { Mass Fraction of } \\
\text { PLA (wt\%) }\end{array}$ & $\begin{array}{c}\text { Mass Fraction of } \\
\text { ESO (wt\%) }\end{array}$ & $\begin{array}{c}\text { Mass Fraction of } \\
\text { Zeolite (wt\%) }\end{array}$ \\
\hline PLA resin & 100 & 0 & 0 \\
PLA/zeolite-2 & 95 & 3 & 2 \\
PLA/zeolite-4 & 93 & 3 & 4 \\
PLA/zeolite-6 & 91 & 3 & 6 \\
PLA/zeolite-8 & 89 & 3 & 8 \\
PLA/zeolite-10 & 87 & 3 & 10 \\
\hline
\end{tabular}

Film sample preparation: The die of the extruder was changed from granular to blowing film; the processing temperatures of the four-heating zoom were $155^{\circ} \mathrm{C}, 170{ }^{\circ} \mathrm{C}$, $175^{\circ} \mathrm{C}$, and $185^{\circ} \mathrm{C}$, the screw rotating speed was $35 \mathrm{rpm}$, the blow-up ratio was 2.6 and the draw ratio was 5.0. The film was blown to a thickness of between $30 \mu \mathrm{m}$ and $80 \mu \mathrm{m}$.

\subsection{Performance Testing and Characterization Methods}

\subsubsection{Analysis of Differential Scanning Calorimetry (DSC)}

A differential scanning calorimeter (DSC 1/700) made by Mettler Toledo Co., Ltd (Zurich, Switzerland) of Switzerland was used to measure the isothermal crystallization behaviour and melting characteristics of the PLA film.

An 8-10 mg sample was weighed and sealed in an aluminium crucible disc, and nitrogen $(50 \mathrm{~mL} / \mathrm{min})$ was used as the protective gas. The initial temperature was $20^{\circ} \mathrm{C}$, the temperature was raised to $200^{\circ} \mathrm{C}$ at a heating rate of $10^{\circ} \mathrm{C} / \mathrm{min}$ [22], and the temperature was kept constant for $3 \mathrm{~min}$ to eliminate the thermal history. The sample was then cooled to room temperature and maintained at a constant temperature for $3 \mathrm{~min}$. Then, the temperature was again raised to $200{ }^{\circ} \mathrm{C}$ at $10{ }^{\circ} \mathrm{C} / \mathrm{min}$, and the second heating curve was recorded. The crystallinity $\left(X_{c}\right)$ was calculated using the following equation:

$$
X_{c}=\frac{\Delta H_{m}}{\Delta H_{m}^{0} \times w} \times 100 \%
$$

where $\Delta H_{m}$ stands for the measured melting enthalpy of the blends; $\Delta H_{m}^{0}$ is the melting enthalpy of PLA with $100 \%$ crystallinity in the ideal state, which is $93.7 \mathrm{~J} / \mathrm{g}$; and $W$ is the mass fraction of PLA in the mixture.

\subsubsection{Analysis of Polarizing Microscopy}

The thin plate sample was pressed between two cover glasses $(20 \mathrm{~mm} \times 20 \mathrm{~mm})$. The sample was heated at $200{ }^{\circ} \mathrm{C}$ for five minutes and then cooled naturally to room temperature. Finally, a polarizing microscope (NP-800RF/TRF) made by Henan Xiongdi Instrument Equipment Company of China was used to observe the crystal form.

\subsubsection{Transparency Test}

According to the GB/T 2410-2008 test method for the transmittance and haze of transparent plastics, a transmittance/haze tester (WGT-S) made by Labthink Electromechanical Technology Company of China was used to measure the transmittance and haze of the PLA film. Equations (2) and (3) below represent the transmittance and haze, respectively, where $\varphi_{1}$ is the luminous flux incident on the surface of the material, $\varphi_{2}$ is the luminous flux passing through the material and $\varphi_{\mathrm{d}}$ is the scattered luminous flux.

$$
\begin{aligned}
& T \mathrm{t}=\frac{\varphi_{1}}{\varphi_{2}} \times 100 \% \\
& H=\frac{\varphi_{\mathrm{d}}}{\varphi_{2}} \times 100 \%
\end{aligned}
$$




\subsubsection{Analysis of Scanning Electron Microscopy (SEM)}

The sample was cut from the film into a small block according to the requirements of the instrument. The impact section (film surface) of the sample was sprayed with gold, and a scanning electron microscope (Regulus 8100, Tokyo, Japan) made by Hitachi High-tech Company of Japan was used to observe the cross-sectional morphology.

\subsubsection{Film Mechanical Properties Test}

According to the GB/T 1040.2-2006 and GB/T 16578.1-2008 plastic tensile test methods, an intelligent electronic tensile testing machine (XLW (EC)) made by Labthink Electromechanical Technology Company of China was used to measure the mechanical properties of the PLA blend film. The longitudinal tensile strength test was performed at a tensile speed of $100 \mathrm{~mm} / \mathrm{min}$ (Figure 1). The longitudinal tear strength test was performed at a tear speed of $200 \mathrm{~mm} / \mathrm{min}$ (Figure 2). The samples were cut along the blown direction. Each experiment was the average of more than 5 samples.

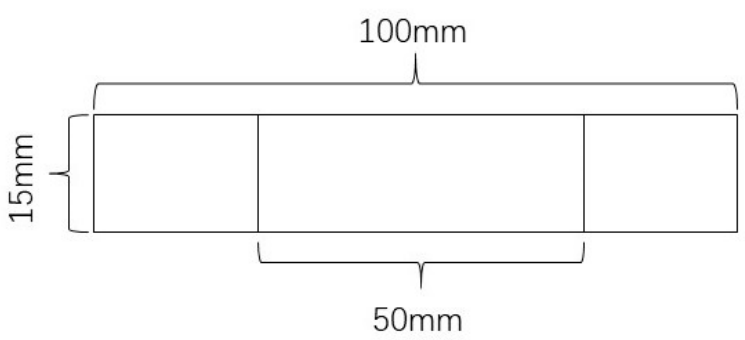

Figure 1. The size of the sample for the tensile strength test.

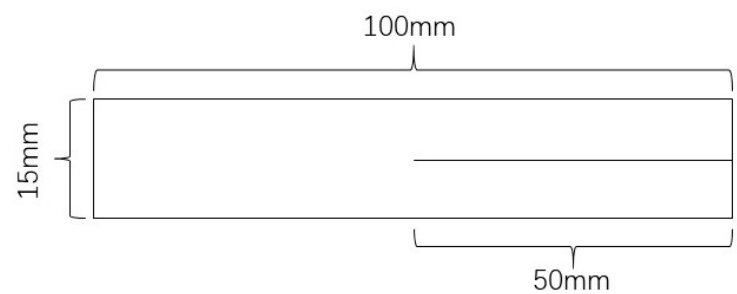

Figure 2. The size of the sample for the tear strength test.

\section{Results and Discussion}

\subsection{Thermodynamic Properties and Processing Conditions of Polylactic Acid Resin}

The Ingeo 4032D PLA resin has a low melt flow rate and poor fluidity and can therefore form stable film bubbles during blow moulding. When PLA resin is used as a packaging film, it requires good heat resistance, stable performance, and poor degradation. The DSC curve of the PLA resin (Figure 3) showed that the melting temperature $\mathrm{T}_{\text {peak }}$ was $163.66^{\circ} \mathrm{C}$. There was no obvious degradation when the temperature was raised to $200^{\circ} \mathrm{C}$.

The single screw extruder is divided into four processing stages: the first is the solid conveying zoom, which is responsible for pushing the solid PLA from the hopper forward, and the temperature should be lower than the melting point of PLA to avoid the softening and melting of granular materials at the blanking port, which can cause bridging phenomena and affect the raw materials entering the extruder. The second is the melting zone where the material begins to soften and melt under the friction of the barrel screw and external heating. The third is the melt conveying zone, where the temperature should reach the melting point, causing the material to melt completely, and the sample should be pushed to the die evenly and stably. The fourth is the die from which the material is extruded. 


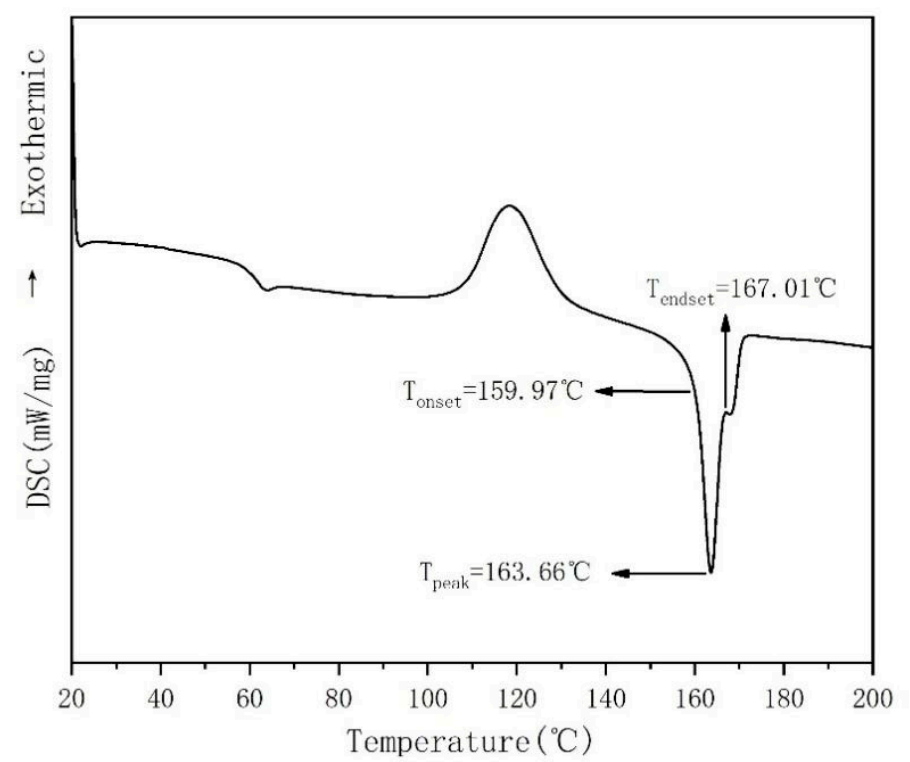

Figure 3. DSC second heating curve of PLA.

With increasing temperature, the viscosity of the material decreases, and the fluidity increases. Therefore, to prevent melt backflow, the temperature of the four zones should be increased in turn (marked as T1, T2, T3). When the same weight of resin was added, the rotation speed was $35 \mathrm{rpm}$, and the influence of temperature on the change in extrusion torque was recorded (Figure 4). The torque curve can be marked in several sections.

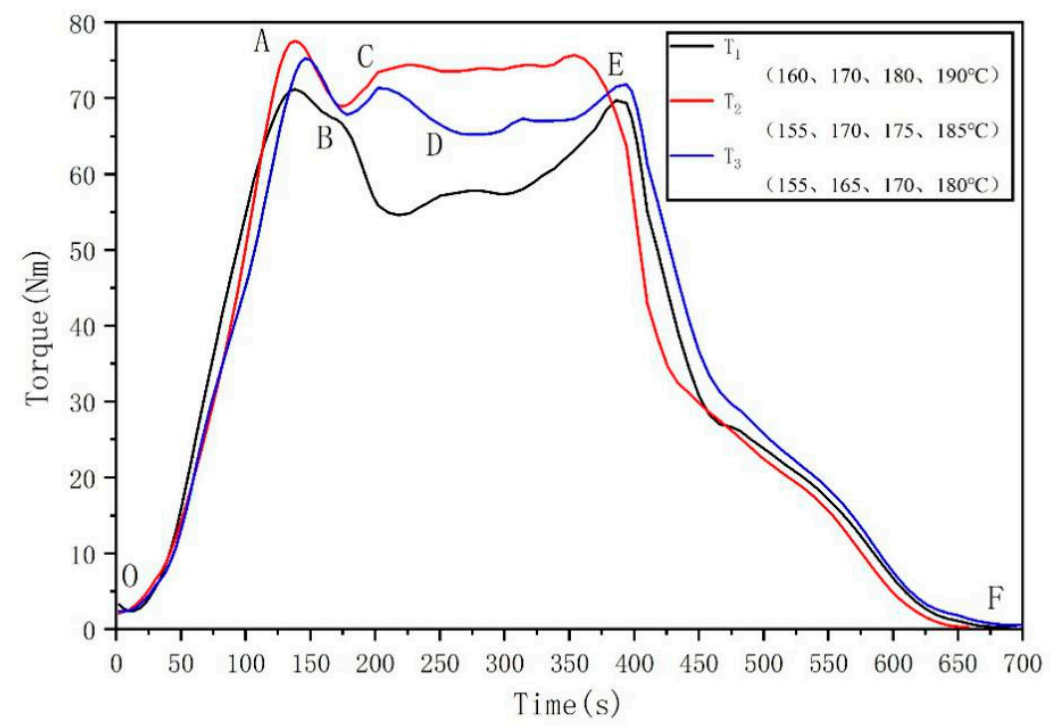

Figure 4. The influence of temperature on the extrusion torque change. OA section: When solid material is added, the torque increases rapidly. $\mathrm{AB}$ section: The material is compressed, and the torque drops to point $\mathrm{B}$. BC section: The material begins to soften or melt, and the torque rises to point C. CD section: The material continuously and completely melts under the action of heat and shear, the fluidity is enhanced, the viscosity is reduced, the force of screw on the material is reduced, and the torque is reduced to point $\mathrm{D}$. DE segment: The torque tends to be stable and is maintained near the $\mathrm{E}$ point. EF section: With the decrease in material, the torque gradually drops to zero.

According to the three curves, the balance torque is T2 $>\mathrm{T} 3>\mathrm{T} 1$. It is important to choose the right processing temperature. If it is too high, it may cause thermal degradation. If it is too low, the material may not melt completely. T2 was selected for the processing 
condition because the torque is relatively stable and slightly higher than the others, which promotes the uniform mixing of materials.

\subsection{Effect of Zeolite Addition on the Crystallinity and Transparency of the PLA Film}

Commercial PLA is a blend of PLLA and PDLA or copolymer PDLLA obtained by the polymerization of LLA and DLLA, respectively [8]. Many important properties of PLA are controlled by the ratio of the D- to L-enantiomers used and the sequence of arrangement of the enantiomers in the polymers. PLLA constitutes the main fraction of PLA derived from renewable sources since the majority of lactic acid obtained from biological sources exists as LLA. PLA with a PLLA content higher than $90 \%$ tends to be crystalline, while PLA with a lower optical purity is amorphous. The melting temperature (Tm), glass transition temperature $(\mathrm{Tg})$, and crystallinity of PLA decrease with decreasing amounts of PLLA [4,27-29]. PLA can be amorphous or semicrystalline depending on its stereochemical structure and thermal history.

Figure 5 presents the DSC second heating curves of PLA and PLA/zeolite blend films at $10{ }^{\circ} \mathrm{C} / \mathrm{min}$. The nonisothermal crystallization and melting parameters of PLA and PLA/zeolite composites obtained from DSC curves are summarized in Table 2.

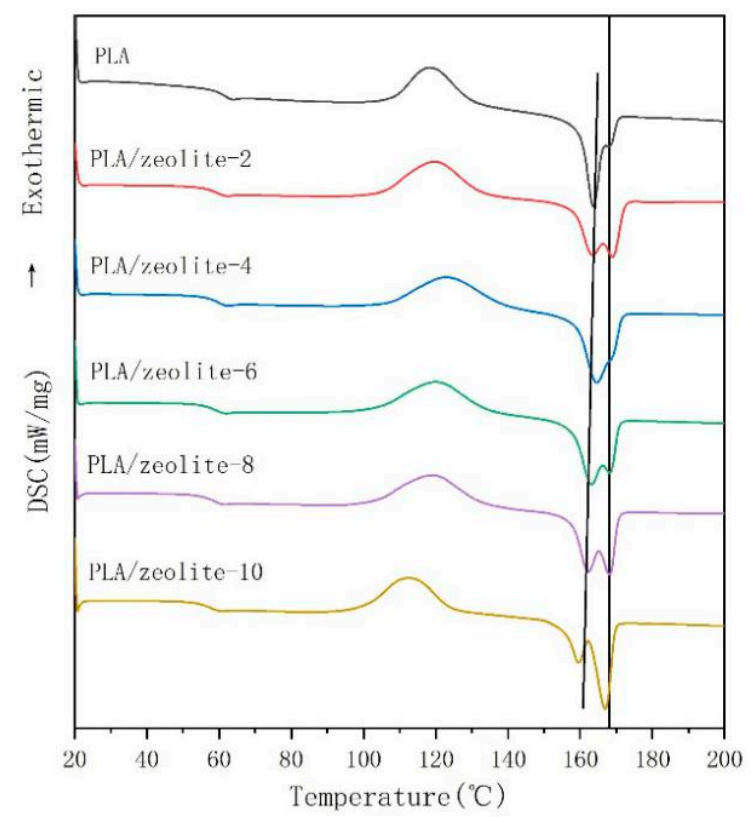

Figure 5. DSC second heating curve of PLA and PLA/zeolite composites.

Table 2. Crystallization and melting parameters of PLA and PLA/zeolite composites.

\begin{tabular}{ccccccccc}
\hline Samples & $\operatorname{Tg}\left({ }^{\circ} \mathbf{C}\right)$ & $\operatorname{Tc}\left({ }^{\circ} \mathbf{C}\right)$ & $\beta-\operatorname{Tm}\left({ }^{\circ} \mathbf{C}\right)$ & $\alpha-\operatorname{Tm}\left({ }^{\circ} \mathbf{C}\right)$ & $\Delta \mathbf{T}\left({ }^{\circ} \mathbf{C}\right)$ & $\beta-X \mathbf{c} / \%$ & $\alpha-X \mathbf{c} \%$ & $\mathbf{X c} / \%$ \\
\hline PLA & 59.50 & 118.28 & 163.66 & 168.11 & 4.45 & 28.33 & 6.30 & 34.63 \\
PLA/zeolite-2 & 57.79 & 119.80 & 163.41 & 169.07 & 5.56 & 20.21 & 16.29 & 36.50 \\
PLA/zeolite-4 & 58.27 & 123.10 & 164.52 & 168.78 & 4.26 & 30.26 & 10.09 & 40.35 \\
PLA/zeolite-6 & 57.41 & 120.27 & 163.09 & 168.11 & 5.02 & 24.49 & 13.97 & 38.50 \\
PLA/zeolite-8 & 56.94 & 119.11 & 162.28 & 168.11 & 5.83 & 22.87 & 17.57 & 40.44 \\
PLA/zeolite-10 & 56.12 & 112.95 & 159.50 & 166.93 & 7.43 & 15.44 & 28.79 & 44.24 \\
\hline
\end{tabular}

Tg: As seen in Figure 5 and Table 2, the glass transition temperature of the blend is slightly lower than that of pure PLA, attributable to the interaction that occurs when ESO and the PLA molecular chains are added; this interaction replaces the interaction between the original PLA molecular chains, weakening the force between the molecular chain segments and reducing the glass transition temperature. 
Tc: Compared with other semicrystalline polymers (polyethylene or polypropylene), PLA crystallizes more slowly. Without further treatment, it is difficult to improve the crystallinity and heat resistance temperature. The appearance of a cold crystallization peak indicates that some of the PLA cannot crystallize due to the supercooling rate from $200{ }^{\circ} \mathrm{C}$ to room temperature. After the second heating, the PLA that could not crystallize became crystallized as the temperature drops, and a large amount of heat was released. When $10 \mathrm{wt} \%$ zeolite was added, the cold crystallization peak became obviously shorter and wider and migrated to the low-temperature region. The results show that the addition of zeolite can obviously accelerate the crystallization rate of PLA.

$\mathrm{Tm}$ : The nucleation of zeolite greatly influences the crystallization process and morphology of PLA, and the melting curves show obvious melting double peaks. One opinion is that the low-temperature peak is due to the melting of the initial crystal, while the high-temperature peak is due to recrystallization that occurs during the heating process, which improves the ordered arrangement of the chain segments in the crystal plate [32]. Another opinion is that PLA can crystallize into three forms $(\alpha, \beta$, and $\gamma)$, a phenomenon generally referred to as polymorphism [33]. Polymorphism in materials science refers to the existence of more than one crystalline structure in a solid material with the same chemical composition [34]. The $\alpha$-structure, which has a Tm of $185{ }^{\circ} \mathrm{C}$, is more stable than the $\beta$-structure, which has a Tm of $175{ }^{\circ} \mathrm{C}$ [35]. The $\beta$-structure of PLA has also been widely investigated [36-42] since Eling et al. [38] first detected the presence of the $\beta$-structure upon hot drawing of the melt-spun or solution-spun PLLA fibres under a high draw ratio. $\beta$-structure crystals are generally prepared by stretching their $\alpha$-structure at high temperature and a high draw ratio. Therefore, it can be inferred that the blown film has a $\beta$-structure.

With increasing zeolite content, the difference between the melting temperature of the $\alpha$-structure and $\beta$-structure crystals and the crystallinity increases, and more stable $\alpha$-structure crystals appear.

PLA was pressed between two coverslips on a hotplate and heated to $200{ }^{\circ} \mathrm{C}$ for melting and then cooled to room temperature for nonisothermal crystallization. Figure 6 shows a polarizing microscope photograph of the blend amplified 100 times. Figure 7 shows the blend amplified 1000 times.

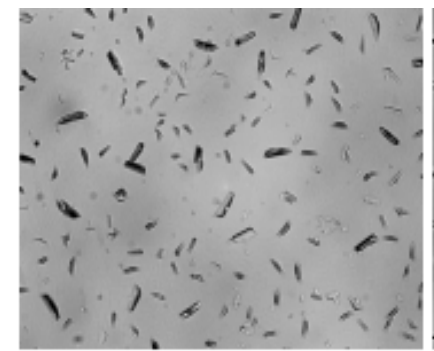

(a)

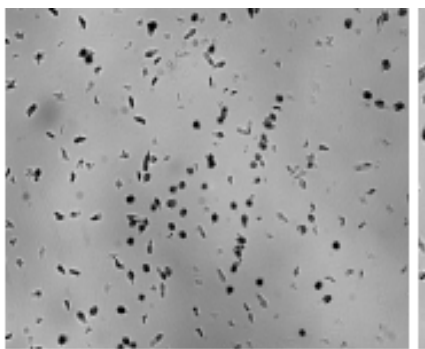

(b)

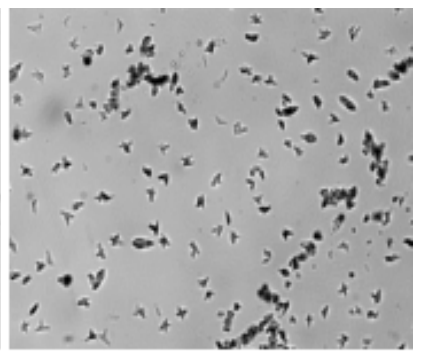

(c)

Figure 6. The polarizing microscope photographs of PLA/zeolite-4 (a), PLA/zeolite-6 (b) and PLA/zeolite-8 (c) amplified 100 times.

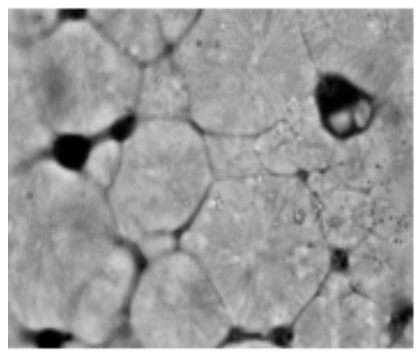

(a)

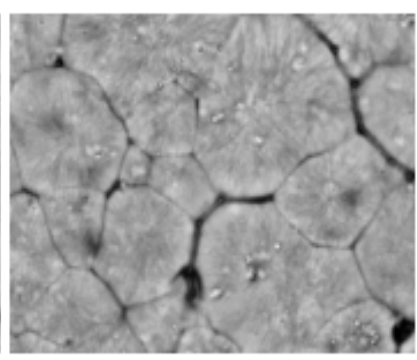

(b)

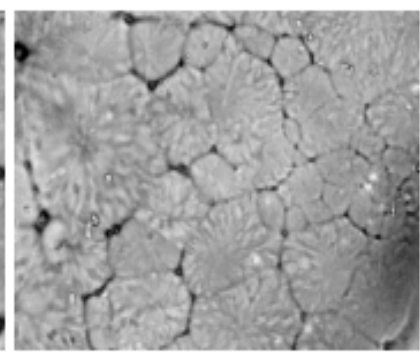

(c)

Figure 7. The polarizing microscope photographs of PLA/zeolite-4 (a), PLA/zeolite-6 (b) and PLA/zeolite-8 (c) amplified 1000 times. 
With the increase in zeolite proportion, the number of spherulites observed in the vision field obviously increases. The average diameter of spherulites with different zeolite proportions is calculated in Table 3. The larger the zeolite proportion is, the smaller the average diameter of the spherulites is. This proves that zeolite acts as a nucleating agent.

Table 3. The average diameter of spherulites with different zeolite proportions.

\begin{tabular}{cc}
\hline Sample & Average Diameter/ $\boldsymbol{\mu m}$ \\
\hline PLA/zeolite-4 & 152.48 \\
PLA/zeolite-6 & 135.74 \\
PLA/zeolite-8 & 96.57 \\
\hline
\end{tabular}

Figure 8 shows the effect of zeolite on the transmittance and haze of the PLA films. The light transmittance remains stable, but the haze increases considerably. Zeolite as a nucleating agent causes light scattering in small crystals.

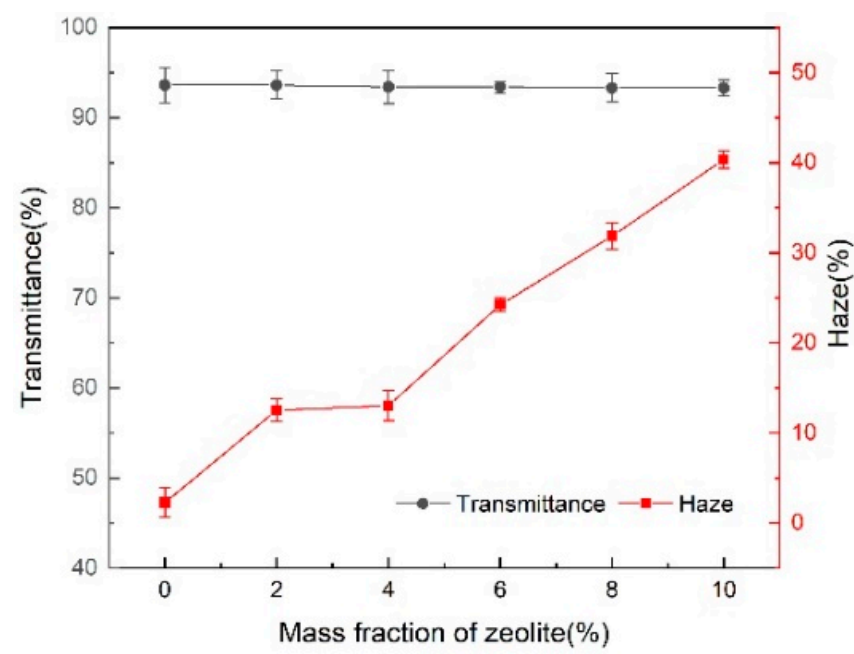

Figure 8. The effect of zeolite on the light transmittance and haze of PLA composites.

\subsection{Effect of ESO and Zeolite Addition on the Structure and Physical Properties of PLA Films}

To maintain the biodegradability and nontoxicity of the PLA, green plasticizers and vegetable oil-based plasticizers are widely used to improve the brittleness and reduce the price of PLA mixture, as the price of ESO is lower than of PLA resin [43]; 3\% of ESO can also reduce the cost of product.

ESO was prepared from soybean oil after oxidation treatment. It is colourless and nontoxic, meets the requirements of green environmental protection, and is biodegradable and inexpensive. Its boiling point is $150{ }^{\circ} \mathrm{C}$, it has excellent thermal stability, light stability, water resistance and oil resistance, and it can endow products with higher strength and better weather resistance. ESO contains many epoxy groups (Figure 9). The oxygen-containing ternary ring structure on these groups has a high tension and can polymerize with hydroxyl groups, anhydride groups and unsaturated groups containing active hydrogen atoms.

Plasticizers can improve the brittleness of PLA and reduce the strength and rigidity and other mechanical properties, though filling reinforcers are needed. Zeolite is a hydrous aluminosilicate mineral with a network structure. All kinds of zeolite crystals have nanoscale crystal structures and uniform microporous structures, which gives them high specific surface areas, stable chemical properties, good thermal stability, and high adsorption capacities. The internal channel size is between 3-10 A, which fits the characteristics of adsorbing molecules. The $3 \mathrm{~A}$ molecular sieve is a zeolite crystal with the structure of two four-membered rings. The average particle size is $2-5 \mu \mathrm{m}$. It can be used as a nanomaterial to reinforce the matrix. 


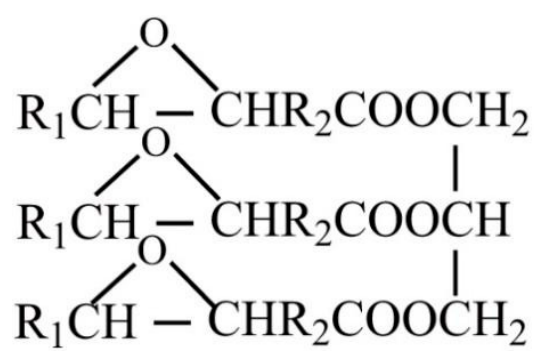

(a)

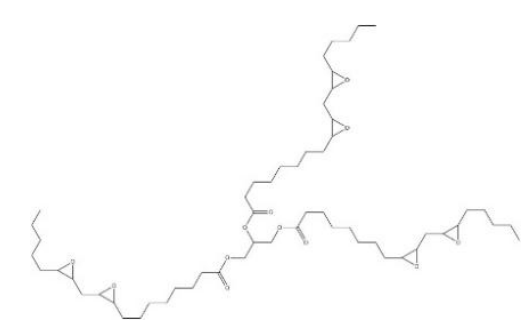

(b)

Figure 9. The skeletal structure (a) and stereoscopic structure (b) of ESO.

PLA is a semicrystalline material in the solid-state (Figure 10). Zeolite was soaked in ESO and mixed with PLA to granulate, and then it was blown into a film. It is thought that both the zeolite and ESO insert into the amorphous phase of PLA to form a blended structure in a reinforced network to improve the rigidity, yield stress and machinability of the material.

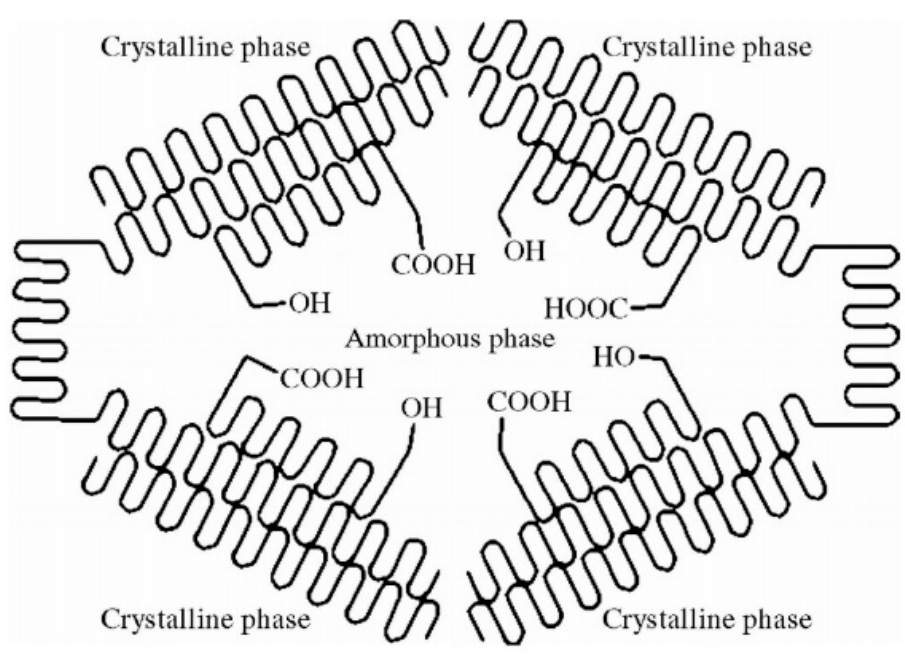

Figure 10. Schematic depiction of solid-state polycondensation.

Figure 11 shows an SEM image of the dispersion of zeolite particles on the surface of the PLA matrix after it was fixed with $3 \mathrm{wt} \%$ ESO and the mass fraction of zeolite was increased. The principle of SEM is based on the different conductivity of materials. The conductivity of zeolite is much higher than that of PLA. So the highlighted particles must be zeolite and the dark continuous phase is PLA resin [24]. While the image of pure PLA shows a dark surface, this image contains white dots that are believed to be zeolite particles. The zeolite particles can be evenly dispersed in the PLA matrix at a $2 \mathrm{wt} \%$ dose. Figure 12 shows the inferred average size of the particle. Particles between 1 and $100 \mathrm{~nm}$ are considered to be nano-reinforced [44]. At doses greater than $2 \mathrm{wt} \%$, most of the particles are oversized. Agglomeration occurs, which may greatly compromise the physical properties. 


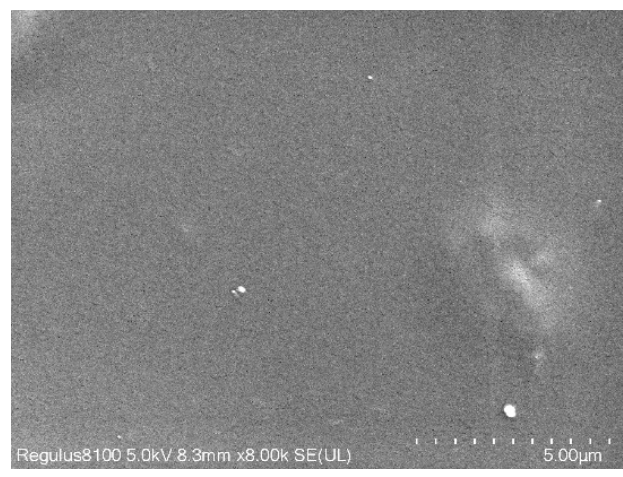

(a)

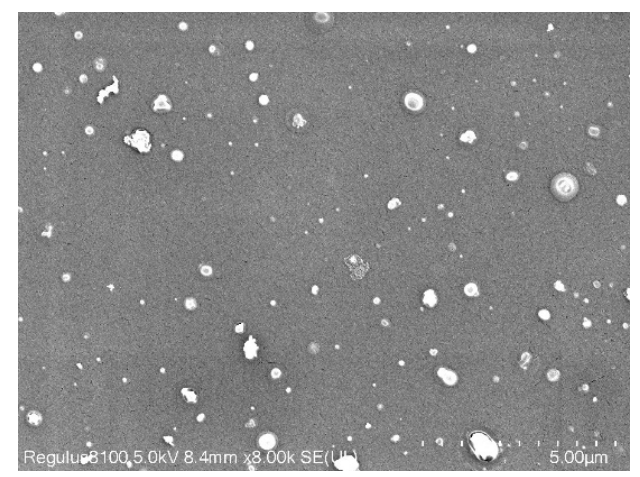

(c)

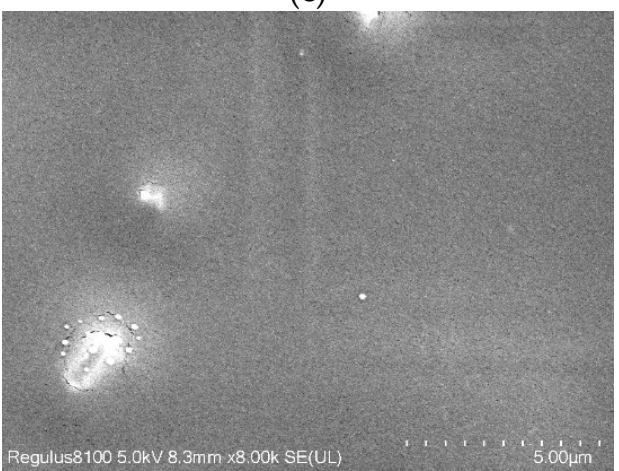

(e)

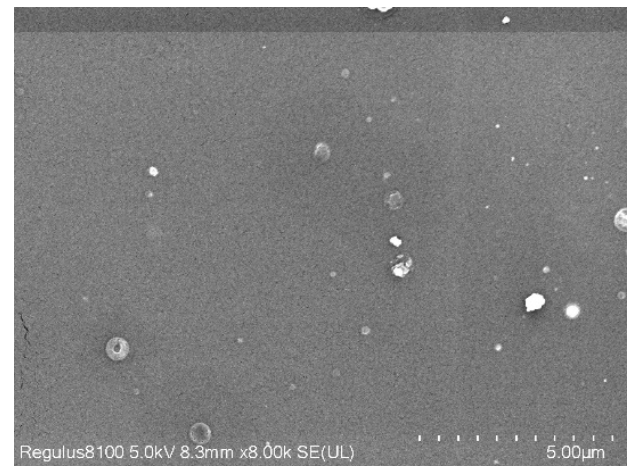

(b)

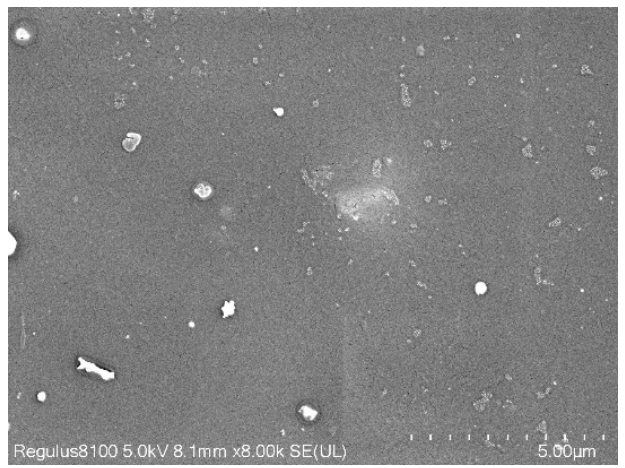

(d)

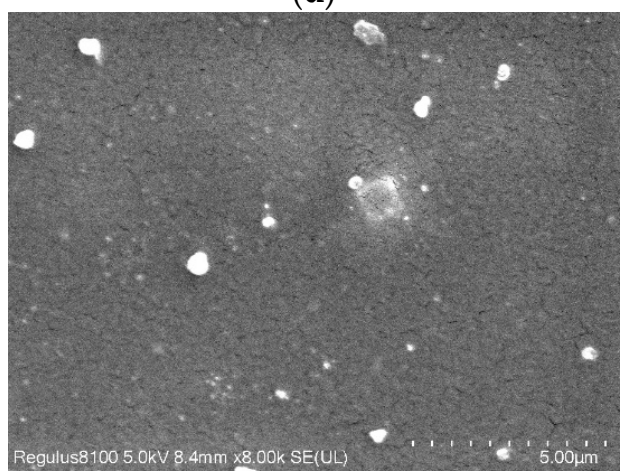

(f)

Figure 11. SEM images of PLA (a) and PLA/zeolite composites magnified 8000 times with different zeolite concentrations: (b-f) shows $2,4,6,8$ and $10 \mathrm{wt} \%$, respectively.

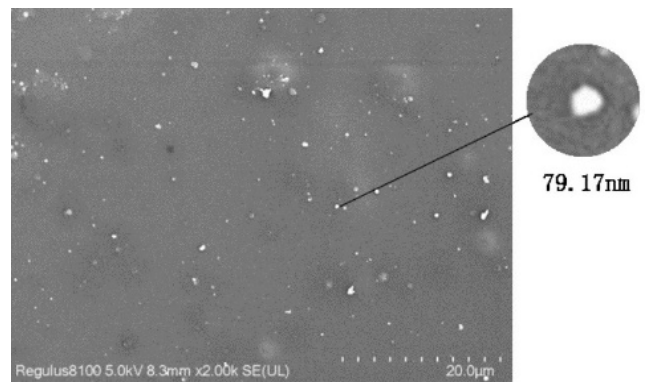

(a)

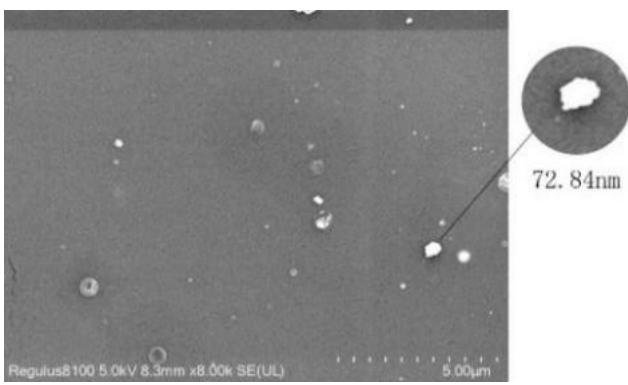

(b)

Figure 12. Dispersion size of zeolite in PLA/zeolite-2 magnified 2000 times (a) and 8000 times (b).

Tensile samples were cut along the blown direction of the film. The longitudinal tensile strength and elongation are shown in Figure 13. 


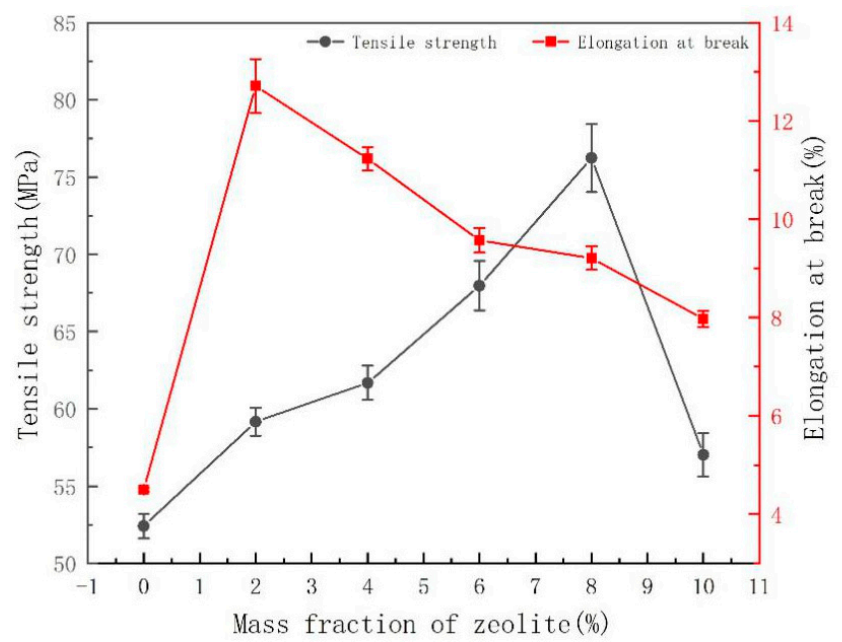

Figure 13. Effect of zeolite mass fraction on the mechanical properties of PLA composite films.

This figure shows the effect of the zeolite mass fraction on the physical properties of PLA films. The tensile strength curve has a peak at $8 \mathrm{wt} \%$ zeolite, and the elongation curve has a peak at $2 \mathrm{wt} \%$ zeolite. The sample with $10 \mathrm{wt} \%$ zeolite has a higher tensile strength and higher elongation than pure PLA. It seems that adding $10 \mathrm{wt} \%$ zeolite and $3 \mathrm{wt} \%$ ESO can even improve the comprehensive properties of PLA, but if the dispersion is finer, then the performance is better.

\section{Conclusions}

A melting extrusion blow moulding method was used to process a series of $\mathrm{PLA} / \mathrm{ESO} /$ zeolite blend films under the most ideal experimental conditions in our laboratory. Zeolite acted as a nucleating agent, increasing the crystallinity and haze of the PLA film, decreasing the size, and changing more crystal forms from $\beta$-structures to $\alpha$ structures. SEM indicated that the zeolite particles agglomerated when the mass fraction of zeolite was higher. When $10 \mathrm{wt} \%$ zeolite and $3 \mathrm{wt} \%$ ESO were added, the tensile strength and elongation were also higher than those of pure PLA. Zeolite was also shown to be a reinforcing filler and ESO was shown to be a plastizer. Our future work will be focused on the dispersion of zeolite to gain an economically active packaging film.

Author Contributions: S.W.: Resources, Writing—original draft, Investigation, Data curation. H.G.: Conceptualization, Supervision. B.L.: Software, Formal analysis, Visualization. Y.Q.: Data curation, Validation. All authors have read and agreed to the published version of the manuscript.

Funding: This research was funded by Qilu University of Technology (Shandong Academy of Sciences), grant number QLUTGJHZ2018028.

Institutional Review Board Statement: Not applicable.

Informed Consent Statement: Not applicable.

Data Availability Statement: Not applicable.

Conflicts of Interest: The authors declare that they have no known competing financial interests or personal relationships that could have appeared to influence the work reported in this paper.

\section{References}

1. Han, Y.; Shi, J.; Mao, L.; Wang, Z.; Zhang, L. Improvement of Compatibility and Mechanical Performances of PLA/PBAT Composites with Epoxidized Soybean Oil as Compatibilizer. Ind. Eng. Chem. Res. 2020, 59, 21779-21790. [CrossRef]

2. Södergård, A.; Stolt, M. Properties of lactic acid based polymers and their correlation with composition. Prog. Polym. Sci. 2002, 27, 1123-1163. [CrossRef]

3. Chaiwong, C.; Rachtanapun, P.; Wongchaiya, P.; Auras, R.; Boonyawan, D. Effect of plasma treatment on hydrophobicity and barrier property of polylactic acid. Surf. Coat. Technol. 2010, 204, 2933-2939. [CrossRef] 
4. Lim, L.T.; Auras, R.; Rubino, M. Processing technologies for poly(lactic acid). Prog. Polym. Sci. 2008, 33, 820-852. [CrossRef]

5. Gross, R.; Kalra, B. Biodegradable Polymers for the Environment. Science 2002, 297, 803-807. [CrossRef] [PubMed]

6. Vink, E.; Davies, S. Life Cycle Inventory and Impact Assessment Data for 2014 IngeoTM Polylactide Production. Ind. Biotechnol. 2015, 11, 167-180. [CrossRef]

7. Gorrasi, G.; Vittoria, V.; Murariu, M.; Ferreira, A.D.S.; Alexandre, M.; Dubois, P. Effect of Filler Content and Size on Transport Properties of Water Vapor in PLA/Calcium Sulfate Composites. Biomacromolecules 2008, 9, 984-990. [CrossRef]

8. Auras, R.; Harte, B.; Selke, S. An Overview of Polylactides as Packaging Materials. Macromol. Biosci. 2004, 4, 835-864. [CrossRef]

9. Kovalchuk, A.; Fischer, W.; Epple, M. Controlled Release of Goserelin from Microporous Polyglycolide and Polylactide. Macromol. Biosci. 2005, 5, 289-298. [CrossRef] [PubMed]

10. Nagarajan, V.; Zhang, K.; Misra, M.; Mohanty, A.K. Overcoming the Fundamental Challenges in Improving the Impact Strength and Crystallinity of PLA Biocomposites: Influence of Nucleating Agent and Mold Temperature. ACS Appl. Mater. Interfaces 2015, 7, 11203-11214. [CrossRef]

11. Albertsson, A.-C.; Varma, I. Aliphatic Polyesters: Synthesis, Properties and Applications. In Degradable Aliphatic Polyesters; Springer: Berlin, Germany, 2001; Volume 157, pp. 1-40.

12. Albertsson, A.-C.; Varma, I.K. Recent Developments in Ring Opening Polymerization of Lactones for Biomedical Applications. Biomacromolecules 2003, 4, 1466-1486. [CrossRef] [PubMed]

13. Amass, W.; Amass, A.; Tighe, B. A review of biodegradable polymers: Uses, current developments in the synthesis and characterization of biodegradable polyesters, blends of biodegradable polymers and recent advances in biodegradation studies. Polym. Int. 1998, 47, 89-144. [CrossRef]

14. Bai, H.; Huang, C.; Xiu, H.; Zhang, Q.; Deng, H.; Wang, K.; Chen, F.; Fu, Q. Significantly Improving Oxygen Barrier Properties of Polylactide via Constructing Parallel-Aligned Shish-Kebab-Like Crystals with Well-Interlocked Boundaries. Biomacromolecules 2014, 15, 1507-1514. [CrossRef] [PubMed]

15. Jackson, C.; Keating, M.Y.; Gardner, K. Material Design in Poly(Lactic Acid) Systems: Block Copolymers, Star Homo and Copolymers, and Stereocomplexes. J. Macromol. Sci. Part A 1996, 33, 1497-1530. [CrossRef]

16. Jagur-Grodzinski, J. Polymers for tissue engineering, medical devices, and regenerative medicine. Concise general review of recent studies. Polym. Adv. Technol. 2006, 17, 395-418. [CrossRef]

17. Ouchi, T.; Ohya, Y. Design of Lactide Copolymers as Biomaterials. J. Polym. Sci. Part A Polym. Chem. 2004, 42, 453-462. [CrossRef]

18. Vainionpää, S.; Rokkanen, P.; Törmälä, P. Surgical applications of biodegradable polymers in human tissues. Prog. Polym. Sci. 1989, 14, 679-716. [CrossRef]

19. Varma, I.K.; Albertsson, A.-C.; Rajkhowa, R.; Srivastava, R.K. Enzyme catalyzed synthesis of polyesters. Prog. Polym. Sci. 2005, 30, 949-981. [CrossRef]

20. Gupta, A.; Katiyar, V. Cellulose Functionalized High Molecular Weight Stereocomplex Polylactic Acid Biocomposite Films with Improved Gas Barrier, Thermomechanical Properties. ACS Sustain. Chem. Eng. 2017, 5, 6835-6844. [CrossRef]

21. Singh, A.A.; Genovese, M.E.; Mancini, G.; Marini, L.; Athanassiou, A. Green Processing Route for Polylactic Acid-Cellulose Fiber Biocomposites. ACS Sustain. Chem. Eng. 2020, 8, 4128-4136. [CrossRef]

22. Trifol, J.; Plackett, D.; Szabo, P.; Daugaard, A.E.; Giacinti Baschetti, M. Effect of Crystallinity on Water Vapor Sorption, Diffusion, and Permeation of PLA-Based Nanocomposites. ACS Omega 2020, 5, 15362-15369. [CrossRef]

23. Gigante, V.; Canesi, I.; Cinelli, P.; Coltelli, M.B.; Lazzeri, A. Rubber Toughening of Polylactic Acid (PLA) with Poly(butylene adipate-co-terephthalate) (PBAT): Mechanical Properties, Fracture Mechanics and Analysis of Ductile-to-Brittle Behavior while Varying Temperature and Test Speed. Eur. Polym. J. 2019, 115, 125-137. [CrossRef]

24. Li, F.; Zhang, C.; Weng, Y.-X. Improvement of the Gas Barrier Properties of PLA/OMMT Films by Regulating the Interlayer Spacing of OMMT and the Crystallinity of PLA. ACS Omega 2020, 5, 18675-18684. [CrossRef]

25. Rhim, J.-W.; Hong, S.-I.; Ha, C.-S. Tensile, water vapor barrier and antimicrobial properties of PLA/nanoclay composite films. LWT Food Sci. Technol. 2009, 42, 612-617. [CrossRef]

26. Yao, C.; Hongmei, W.; Wu, L. Progress in Modification of Poly(lactic acid) by Citrate Ester and Epoxy Soybean Oil Plasticizer. Eng. Plast. Appl. 2020, 48, 164-169.

27. Urayama, H.; Moon, S.-I.; Kimura, Y. Microstructure and Thermal Properties of Polylactides with Different L- and D-Unit Sequences: Importance of the Helical Nature of the L-Sequenced Segments. Macromol. Mater. Eng. 2003, 288, 137-143. [CrossRef]

28. Tsuji, H.; Ikada, Y. Crystallization from the melt of poly(lactide)s with different optical purities and their blends. Macromol. Chem. Phys. 1996, 197, 3483-3499. [CrossRef]

29. Dorgan, J.; Janzen, J.; Clayton, M.; Hait, S.; Knauss, D. Melt rheology of variable L-content poly(lactic acid). J. Rheol. 2005, 49, 607-619. [CrossRef]

30. Huang, Y.; Wang, Y.; Li, Y.; Luo, C.; Yang, C.; Shi, W.; Li, L. Covalent Immobilization of Polypeptides on Polylactic Acid Films and Their Application to Fresh Beef Preservation. J. Agric. Food Chem. 2020, 68, 10532-10541. [CrossRef]

31. Liu, M.; Lyu, S.; Peng, L.; Cai, L.; Huang, Z.; Lyu, J. Improvement of Toughness and Mechanical Properties of Furfurylated Wood by Biosourced Epoxidized Soybean Oil. ACS Sustain. Chem. Eng. 2021, 9, 8142-8155. [CrossRef]

32. Yasuniwa, M.; Tsubakihara, S.; Iura, K.; Ono, Y.; Dan, Y.; Takahashi, K. Crystallization behavior of poly(l-lactic acid). Polymer 2006, 47, 7554-7563. [CrossRef] 
33. Lin, L.; Deng, C.; Lin, G.-P.; Wang, Y.-Z. Super Toughened and High Heat-Resistant Poly(Lactic Acid) (PLA)-Based Blends by Enhancing Interfacial Bonding and PLA Phase Crystallization. Ind. Eng. Chem. Res. 2015, 54, 5643-5655. [CrossRef]

34. Pan, P.; Inoue, Y. Polymorphism and isomorphism in biodegradable polyesters. Prog. Polym. Sci. 2009, 34, 605-640. [CrossRef]

35. Arnoult, M.; Dargent, E.; Mano, J.F. Mobile amorphous phase fragility in semi-crystalline polymers: Comparison of PET and PLLA. Polymer 2007, 48, 1012-1019. [CrossRef]

36. Takahashi, K.; Sawai, D.; Yokoyama, T.; Kanamoto, T.; Hyon, S.H. Crystal transformation from the a- to the b-form upon tensile drawing of poly(l-lactic acid). Polymer 2004, 45, 4969-4976. [CrossRef]

37. Sawai, D.; Yokoyama, T.; Kanamoto, T.; Sungil, M.; Hyon, S.-H.; Myasnikova, L.P. Crystal Transformation and Development of Tensile Properties upon Drawing of Poly(L-lactic acid) by Solid-State Coextrusion: Effects of Molecular Weight. Macromol. Symp. 2006, 242, 93-103. [CrossRef]

38. Eling, B.; Gogolewski, S.; Pennings, A.J. Biodegradable materials of poly(l-lactic acid): 1. Melt-spun and solution-spun fibres. Polymer 1982, 23, 1587-1593. [CrossRef]

39. Puiggali, J.; Ikada, Y.; Tsuji, H.; Cartier, L.; Okihara, T.; Lotz, B. The frustrated structure of poly(l-lactide). Polymer 2000 41, 8921-8930. [CrossRef]

40. Brant, D.A.; Tonelli, A.E.; Flory, P.J. The Configurational Statistics of Random Poly(lactic acid) Chains. II. Theory. Macromolecules 1969, 2, 228-235. [CrossRef]

41. Leenslag, J.W.; Pennings, A.J. High-strength poly(l-lactide) fibres by a dry-spinning/hot-drawing process. Polymer 1987, 28, 1695-1702. [CrossRef]

42. Sawai, D.; Takahashi, K.; Sasashige, A.; Kanamoto, T. Preparation of Oriented $\beta$-Form Poly(l-lactic acid) by Solid-State Coextrusion: Effect of Extrusion Variables. Macromolecules 2003, 36, 3601-3605. [CrossRef]

43. Qiu-en, L. Research Progress of Biodegradable Materials and Analysis of Domestic and Foreign Industry Status. J. Hunan Packag. 2021, 36, 31-34.

44. Chang-jiao, S.; Hai-xin, C.; Yan, W.; Zhang-hua, Z.; Xiang, Z.; Bo, C. Studies on Applications of Nanomaterial and Nanotechnology in Agriculture. J. Agric. Sci. Technol. 2016, 18, 18-25. 